\title{
Breast Cancer and miR-SNPs: The Importance of miR Germ-Line Genetics
}

\author{
Poonam Malhotra ${ }^{\dagger}$, Graham H. Read ${ }^{+}(\mathbb{D}$ and Joanne B. Weidhaas $*$ (D) \\ Department of Radiation Oncology, David Geffen School of Medicine, University of California, Los Angeles, \\ CA 90001, USA; PMalhotra@mednet.ucla.edu (P.M.); gread@ucla.edu (G.H.R.) \\ * Correspondence: jweidhaas@mednet.ucla.edu \\ † These authors contributed equally to this work.
}

Received: 1 February 2019; Accepted: 15 March 2019; Published: 20 March 2019

\begin{abstract}
Recent studies in cancer diagnostics have identified microRNAs (miRNAs) as promising cancer biomarkers. Single nucleotide polymorphisms (SNPs) in miRNA binding sites, seed regions, and coding sequences can help predict breast cancer risk, aggressiveness, response to stimuli, and prognosis. This review also documents significant known miR-SNPs in miRNA biogenesis genes and their effects on gene regulation in breast cancer, taking into account the genetic background and ethnicity of the sampled populations. When applicable, miR-SNPs are evaluated in the context of other patient factors, including mutations, hormonal status, and demographics. Given the power of miR-SNPs to predict patient cancer risk, prognosis, and outcomes, further study of miR-SNPs is warranted to improve efforts towards personalized medicine.
\end{abstract}

Keywords: miR-SNPs; breast cancer; polymorphism; 3'UTR; predictive biomarkers

\section{Introduction}

Breast cancer is the second most common form of cancer diagnosed in American women, after skin cancer. It is among the most frequently diagnosed cancers worldwide, with 2.08 million new cases in 2018 (11.6\% of all cancer cases) [1]. According to American Cancer Society estimates, an American woman has about a $12 \%$ average lifetime risk of developing breast cancer. Worldwide, breast cancer led to about 626,000 mortalities in 2018 , representing $6.6 \%$ of cancer deaths-the second-leading cause of cancer death among women [1,2]. Etiology of breast cancer varies according to age of onset, menopausal status of women, exposure to hormone replacement therapies (HRTs), and patient ethnicity [3]. These multiple factors have been associated with differences in risk and outcome.

The first documented involvement of microRNAs (miRNAs) in human cancers was when miR-15 and miR-16-1 were found to be downregulated in chronic lymphocytic leukemia (CLL) [4], revealing a new class of oncogenic miRNAs (oncomiRs) differentially regulated in cancer. Since then, numerous other oncomiRs have been identified, including oncogenic [5] and tumor suppressive miRNAs [6]. Atypical miRNA expression varies between tumor types, and can exert a range of functional effects depending on the cellular context [7].

miRNA expression and targeting can be significantly altered by the presence of single nucleotide polymorphisms (SNPs). SNPs are the most frequently encountered point mutations in the genome, with the first genomic SNP being identified as early as 1976 [8]. Since then, over 84 million SNPs have been documented in the human genome [9], including many in miRNA primary sequences, miRNA target sites, or miRNA biogenesis genes, which we refer to as miR-SNPs $[10,11]$. The overall effect of a miR-SNP on miRNA function depends on its location-miR-SNPs can result in over-expression, degradation, or transcriptional or translational inhibition of miRNAs or targeted mRNA [12]. 
miR-SNPs located in regulatory regions of genes, at miRNA binding sites, or at quantitative trait loci play a major role in gene function and phenotype (Figure 1). Such miR-SNPs can lead to increased risk of multiple types of cancer, including breast cancer [12]. miR-SNPs in seed regions of miRNAs (regions responsible for miRNA-mRNA binding) can disrupt miRNA binding or be lethal. In addition, by altering sequence homology, SNPs can create new interactions between miRNA seed regions and target mRNA [13] (Figure 1). miR-SNPs in the 3'UTRs of mRNA can alter polyadenylation, protein-mRNA interactions, and miRNA-mRNA interactions. These changes can have significant effects on mRNA stability and translation efficiency [14]. Similarly, SNPs in miRNA sequences, including primary and precursor miRNA sequences, can affect production or stability of these miRNAs, as well as miRNA-mRNA interactions, leading to changes in the expression of miRNA target genes [15]. Changes in miRNAs and their mRNA interactions can also be mediated by alterations to miRNA biogenesis genes, which can be brought about by SNPs in proteins responsible for miRNA processing after transcription [16,17]. All of these types of miR-SNP can be prospective candidates as biomarkers for detecting disease susceptibility, determining prognosis for personalized therapeutic regimens, and ensuring the best clinical management of breast cancer patients [7,18-21]. In this review, we will discuss miR-SNPs found to be important in breast cancer.

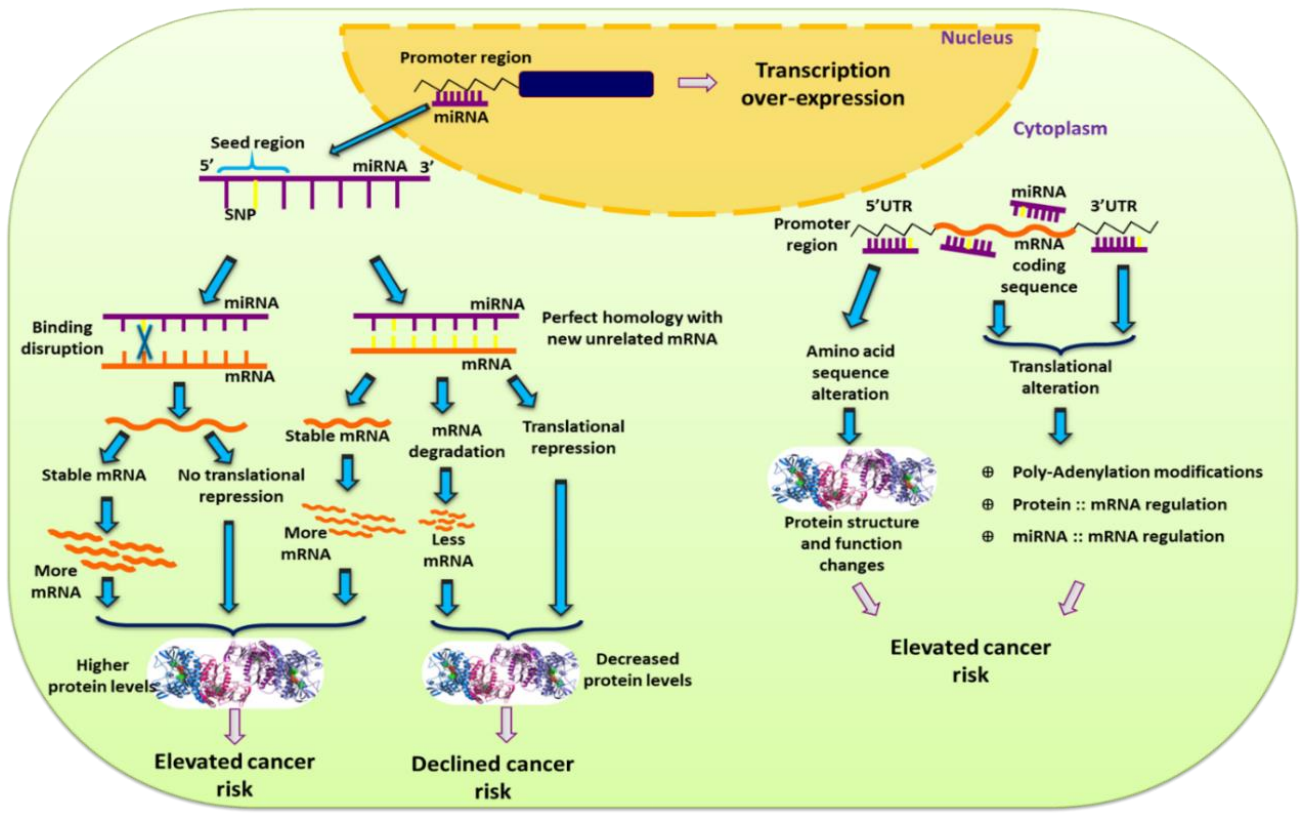

Figure 1. Effect a single nucleotide polymorphism (SNP) exerts in development of cancer risk based on its location in miRNA.

\section{SNPs in miRNA Biogenesis Genes and Breast Cancer}

SNPs affecting proteins responsible for post-transcriptional processing of miRNAs can significantly affect miRNA function. Briefly, miRNAs go through two rounds of enzymatic processing after initial transcription-processes, which implicate miRNA-specific exonucleases, transport proteins, and signaling cascades [22]. The resulting changes to levels of mature miRNA can have significant effects on breast cancer. Significant SNPs have been observed in $3^{\prime}$ UTR, exonic, and intronic regions of miRNA processing genes [21], and at various steps of the miRNA biogenesis pathway [23] (Figure 2).

DROSHA: The nuclear RNase III, Drosha, is the core nuclease that executes the initiation step of miRNA processing, cleaving primary miRNAs to release hairpin-shaped pre-miRNAs. A case-control study of the SNPs rs644236 (C > T) and rs7737174 (A > G) within the DROSHA gene demonstrated increased risk of developing breast cancer $(\mathrm{OR}=1.27$; $\mathrm{CI}$ 0.94-1.73, and $\mathrm{OR}=1.63$; CI 1.01-2.64, for rs644236 and rs7737174, respectively) in Korean post-menopausal women [20]. Another report also 
associated rs2291109 (A > T) in DROSHA with increased breast cancer susceptibility [Odds ratio (OR) $=0.81 ; 95 \%$ Confidence Interval $(\mathrm{CI}) 0.66-0.99]$ in Chinese patients [24].

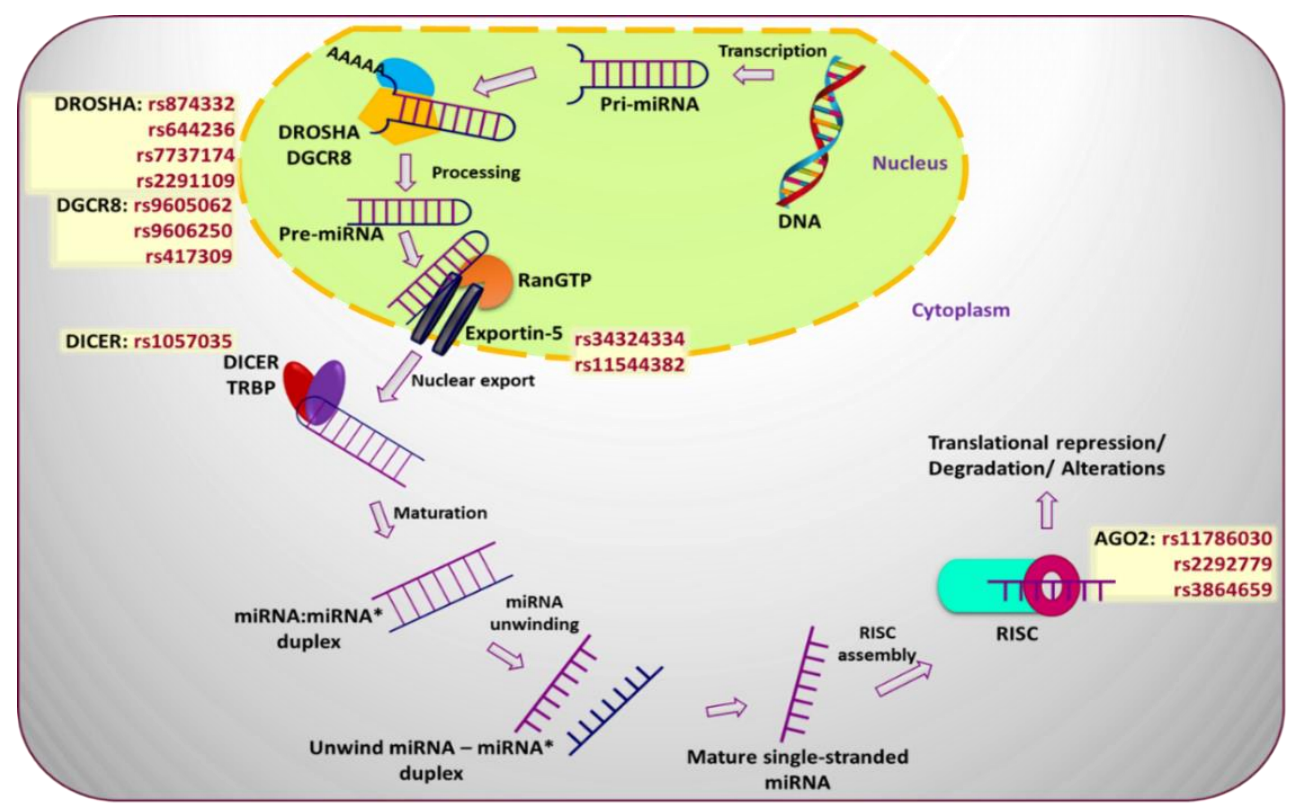

Figure 2. miRNA biogenesis pathway and various single nucleotide polymorphisms (SNPs) occurring at different steps of the pathway that play a pivotal role in prediction of breast cancer risk development.

DGCR8: DGCR8 is believed to be an essential component of the pri-miRNA processing complex with Drosha. A DGCR8 SNP, rs9606250 (A > T) is strongly linked to poor disease-free survival $(\mathrm{HR}=0.21$; CI 0.05-0.84) in Korean breast cancer patients [21]. An additional study in a cohort of 878 Chinese breast cancer patients and 900 controls found that rs417309 (A > G), present in the $3^{\prime}$ UTR of DGCR8 mRNA is associated with a higher risk of developing breast cancer $(\mathrm{OR}=1.50 ; \mathrm{CI} 1.16-1.93)$ by altering binding ability of miR-106b and miR-579 to the DGCR8 3'UTR [24].

XPO5: Alterations to the expression and epigenetic state of Exportin5 (XPO5), responsible for exporting pre-miRNAs from the nucleus, has been associated with risk of breast cancer [25]. The XPO5 missense SNP rs11544382 (A > G) is significantly linked with increased breast cancer risk $(\mathrm{OR}=1.59$; CI 1.06-2.39) compared to homozygous controls in Caucasian populations. Women in post-menopausal stages with the variant allele genotypes of rs11544382 and rs34324334 are also highly prone to developing breast cancer due to altered nucleocytoplasmic transport activity ( $\mathrm{OR}=1.82$ and 1.76, respectively). Increased levels of XPO5 promoter methylation correlate with a reduced risk of breast cancer, consistent with tissue array data showing higher expression of XPO5 in breast cancer cells relative to tumor-adjacent and healthy tissue [25]. This demonstrates that genetic and epigenetic changes to the miRNA biogenesis pathway members can have a significant effect on the risk of breast cancer development.

DICER1: DICER1 is another RNase III protein located in the cytoplasm that cleaves pre-microRNAs into miRNAs. The SNP rs1057035 (C > T), located in the 3'UTR of DICER1, plays a significant role in disease-free survival (DFS) (HR = 1.72; CI 0.99-2.99) and overall survival (OS) $(\mathrm{HR}=2.08 ; \mathrm{CI} 1.01-4.28)$ in Korean breast cancer patients [21]. This miR-SNPs is hypothesized to be present in the binding site of miR-574-3p, affecting miRNA binding and DICER mRNA expression levels [26]. Notably, the SNP is also observed to be linked with significantly elevated risk of breast cancer progression (1.72-fold change) and a 2.08-fold higher breast cancer-associated mortality [21]. However, the $\mathrm{C}$ allele of rs1057035 had been shown to have disparate effects on breast cancer risk, presenting a decreased risk of breast cancer in Asian populations, but not in Caucasian populations (C vs. T: $\mathrm{OR}=0.88, \mathrm{CI} 0.81-0.95, p=0.002$; TC vs. TT: $\mathrm{OR}=0.85, \mathrm{CI} 0.77-0.93, p=0.001$; CC $/ \mathrm{TC}$ vs. TT: 
$\mathrm{OR}=0.86, \mathrm{CI} 0.78-0.94, p=0.001$ ) [27], indicating significant differences in the impact of miR-SNPs based on patient demographics.

AGO2: AGO2 is a critical component of the RISC complex that brings miRNAs to their target $3^{\prime}$ UTR binding sites. A study was undertaken to assess the effect of 41 SNPs in AGO2 on DFS and OS in 488 Korean breast cancer cases [20]. It was found that $\mathrm{rs} 11786030(\mathrm{~A}>\mathrm{G})$ and $\operatorname{rs} 2292779(\mathrm{C}>\mathrm{G})$, located in AGO2, resulting in decreased DFS (HR = 2.62; CI 1.41-4.88 and HR = 1.42; CI 1.06-1.92 for rs11786030 and rs2292779 respectively) as well as poor OS (HR $=2.41 ; \mathrm{CI} 1.05-5.50$ and $\mathrm{HR}=2.94 ; \mathrm{CI}$ 1.52-5.69 for rs11786030 and rs2292779 respectively) in breast cancer patients [21]. Conversely, SNP rs3864659 $(\mathrm{A}>\mathrm{C})$ in $\mathrm{AGO} 2$ protected against breast cancer risk ( $\mathrm{OR}=0.67 ; \mathrm{CI} 0.46-0.96)$ in a Korean population, as observed by a case-control study involving 559 breast cancer cases vs. 567 controls [20].

\section{3'UTR SNPs and Breast Cancer}

Numerous SNPs in miRNA binding sites interfere with miRNA target recognition ability, causing dysregulation of target genes by altering miRNA and mRNA interactions $[12,14]$. When such miR-SNPs occur in an oncogene or a tumor regulatory gene, the resulting alterations in gene regulation can shift cellular homeostasis towards tumorigenesis [12]. Sequence variations in the $3^{\prime}$ UTR of genes important in the stress response or DNA repair alter the function of effector proteins, which causes modifications in the ability to repair damaged DNA, increasing breast cancer risk [28]. The following miR-SNP examples delineate the roles of SNPs in miRNA binding sites in the $3^{\prime}$ UTRs of important genes and their implications in breast cancer.

RAD52: The C allele of SNP rs7963551, positioned in the 3'UTR let-7 binding site of RAD52, reduces risk of breast cancer (OR $=0.84 ; \mathrm{CI}$ : 0.75-0.95) [29]. Similarly, Cao and colleagues found that patients with the AC variant allele and CC allele genotypes of rs7963551 had a significantly lower risk of breast cancer (OR 0.684; CI 0.492-0.951 for AC genotype; OR 0.317, CI 0.200-0.503 for CC genotype) (Table 1). Via qRT-PCR and western blot analysis, they also demonstrated that let-7b plays a pivotal role in downregulating RAD52 expression in MCF-7 and SKBR-3 cells [28]. In addition, women with a higher number of pregnancies and the A allele of rs7963551 were shown to have significantly higher breast cancer risk (OR 2.63, CI 2.03-3.42) [28].

BRCA1: A functional SNP, rs8176318, located in the 3'UTR of BRCA1, has been reported to predict breast (including TNBC) and ovarian cancer risk in a population of Irish women [30]. This SNP is also influenced by estrogen exposure, implying that the variant poses an elevated risk of developing cancer at menopause or upon estrogen withdrawal. The variant TG or TT alleles were compared to a wildtype GG allele in the BRCA1 3'UTR using an in vitro luciferase reporter assay and by immunofluorescence in triple negative breast cancer samples. The authors observed decreased BRCA1 gene expression in TNBC cases bearing TT variants in comparison to GG allele cases. The same results were documented in vitro using TT allele breast cancer cell lines. In accordance with decreased BRCA1 expression, TG or TT allele patients demonstrated elevated breast cancer risk relative to nonvariant patients $(\mathrm{OR}=1.4$; CI 1.1-1.8). Interestingly, variant genotype cases showed four-fold elevated risk of developing Stage IV disease. On the other hand, an elevated risk of breast cancer in $G$ allele variants was observed in African American women ( $\mathrm{OR}=9.5$; CI 1.01-88.80) with specific risk towards developing TNBC $(\mathrm{OR}=12.2, \mathrm{CI} 1.29-115.21)$, emphasizing its utility as a strong genetic marker for predicting potential TNBC risk [31].

Additionally, it has been reported that homozygosity for the A alleles in miR-SNPs rs12516 and rs8176318, located in the $3^{\prime}$ UTR of BRCA1, has a significant association $(p=0.007)$ with familial breast and ovarian cancer in a Thai cohort [32]. An additional BRCA1 3'UTR SNP, rs3092995, induces an elevated breast cancer risk in African American women, with the $\mathrm{G}$ allele predominant in $\mathrm{BC}$ patients, as compared to control subjects (Table 1) [33]. 
Table 1. miR-SNPs and DNA Damage Repair Genes Involved in Breast Cancer Risk.

\begin{tabular}{ccccc}
\hline SNP & Affected miRNA & Related Gene & Breast Cancer Association & References \\
\hline rs7963551 $(\mathrm{C}$ allele $)$ & let-7 & RAD52 & Reduced risk & {$[28,29]$} \\
rs8176318 $(\mathrm{G}>\mathrm{T})$ & miR-639 & BRCA1 & Elevated TNBC risk & {$[30,34]$} \\
rs12516 & miR-1264 & BRCA1 & Elevated risk & {$[32,35]$} \\
rs3092995 & 3'UTR & BRCA1 & Elevated risk & {$[33]$} \\
\hline
\end{tabular}

IQGAP1: IQGAP1 (encoding IQ motif-containing GTPase-activating protein 1) is regulated by miR-124 via a binding site in its $3^{\prime}$ UTR. miR-SNP rs1042538 in the core binding region causes a disruption in this target site sequence. It has been hypothesized that the presence of this miR-SNP in the miR-124 binding site could be predictive of breast cancer risk and prognosis. Zheng and colleagues analyzed the frequency of rs1042538 A/T variants in 1,541 breast cancer cases and 1,598 controls for associated breast cancer risk factors. It was observed that the TT genotype is linked to a lower breast cancer risk as compared to the AA genotype in a Chinese population $(p=0.049, \mathrm{OR}=0.78$; CI 0.61-0.99), implying that the T allele of rs1042538 protects from breast cancer (Table 2). Conversely, the AA genotype of the binding site miR-SNP is linked with increased breast cancer risk due to downregulation of IQGAP1 protein expression [12].

ITGB4: Brendle and colleagues documented the involvement of integrins in breast cancer risk and clinical outcome in a Swedish case-control study. They showed that the presence of the A variant of miR-SNP rs743554 in the ITGB4 3'UTR was strongly associated with specific risk of developing ER-negative breast cancers and worse overall survival in comparison to those with the wildtype alleles (OR 2.09; CI 1.19-3.67) (Table 2). It was also shown by in silico analysis that this SNP impairs miR-34a binding to the ITGB4 $3^{\prime}$ UTR seed region [36].

ESR1: rs2747648 is present in the 3'UTR miRNA binding site of ESR1, leading to increased ESR151 expression levels due to a lack of miR-453-mediated repression [37] (Table 2). A case-control study in a German cohort of 1223 breast cancer families and 1495 controls demonstrated that the $\mathrm{T}$ allele variant of this miR-SNP was association with elevated breast cancer risk in pre-menopausal women (OR 0.60; CI 0.41-0.89) [37]. Similarly, other researchers noted that pre-menopausal women bearing C allele genotypes demonstrated a lower risk of developing breast cancer and had depleted levels of ESR1 in clinical studies [38,39].

TGFB1: It has been reported that individuals with the AG genotype of SNP rs334348 in the $3^{\prime} \mathrm{UTR}$ of TGFBR1 are more prone to breast cancer ( $\mathrm{OR}=2.2 ; \mathrm{CI} 1.29-4.07 ; p=0.005)$. The $\mathrm{G}$ allele was shown to be targeted by miR-628-5p with higher efficacy than its A allele counterpart in vitro [14]. The same study observed that SNP rs1982073 in TGFB1 could exert its effect on gene expression by altering interaction with miR-187, and CC carriers of rs1982073 exhibited an increased risk of breast cancer $(\mathrm{OR}=1.4, \mathrm{CI}=1.1-2.0 ; p=0.04)$ [14]. They also noted that miR-628-5p represses TGFBR1, in a manner dependent on rs334348 variant inside the $3^{\prime}$ UTR miRNA target sequence. Expression of TGFBR1 was $80 \%$ of control levels in cells with the AA genotype versus $50 \%$ of control levels in cells with the CC genotype) (Table 2). In addition, rs1982073 TGFB1 variant was associated with lower TGFB1 expression levels at early tumorigenic stages, while elevated TGFB1 levels were observed in advanced metastatic phases, linked to simultaneous miR-187 expression level fluctuations in the presence of $\mathrm{T}$ variant genotypes [14].

TOPBP1: Topoisomerase IIb binding protein 1 (TOPBP1) is reported to possess miR-SNP rs115160714. Three miRNAs (miR-3138, miR-4302, and miR-1207-5p) are hypothesized to bind TOPBP1 mRNA at its $3^{\prime}$ UTR. CT and TT variants of rs115160714 are associated with higher breast cancer risk in comparison to CC genotype in Caucasian populations (OR 3.54, CI 1.56-8.39; OR 5.40, CI 0.63-46.64, respectively) (Table 2). It was noted that a grade three tumor was more often reported in individual cases bearing a $\mathrm{T}$ variant allele. In addition, patients with $\mathrm{CT}$ or TT genotypes were observed to have elevated levels of TOPBP1 mRNA and protein [40,41]. 
MMP9: Matrix Metalloproteinases are frequently overexpressed in multiple cancers, and MMP overexpression correlates with increased invasion [42] and poorer prognosis [43]. The C allele of the miR-SNP rs1056628 has been documented to affect miR-491-5p binding to the MMP9 $3^{\prime} U T R$, preventing miRNA-mediated inhibition. In vitro analysis demonstrated that cells transfected with C allele-bearing reporter plasmids of the MMP9 $3^{\prime}$ UTR had significantly lower miR-491-5p binding relative to cells transfected with the wildtype A allele. The same study also demonstrated that the presence of the $\mathrm{C}$ allele imparts a significantly higher risk of breast cancer in an Iranian population (OR 3.23, CI 1.34-7.79). Similarly, C allele patients were more likely to have metastases (OR 1.9, CI 1.21-6.8), consistent with higher expressions of MMP9 [44].

Table 2. miR-SNPs and Related Genes Involved in Breast Cancer Risk.

\begin{tabular}{ccccc}
\hline SNP & Affected miRNA & Related Gene & Breast Cancer Association & References \\
\hline rs743554 & miR-34a & ITGB4 & Elevated risk & {$[36]$} \\
rs1042538 $(\mathrm{A}>\mathrm{T})$ & miR-124 & IQGAP1 & Reduced risk & {$[12]$} \\
rs2747648 & miR-453 & ESR1 & Elevated risk & {$[37]$} \\
rs334348 & miR-628-5p & TGFBR1 & Elevated risk & {$[14]$} \\
rs1982073-TGFB1 & miR-187 & TGFB1 & Elevated risk & {$[14]$} \\
rs1056628 & miR-491-5p & MMP9 & Elevated risk & {$[44,45]$} \\
\hline
\end{tabular}

\section{The KRAS-Variant and Breast Cancer Risk}

Kirsten Rat Sarcoma Viral Oncogene (KRAS) is a frequently mutated oncogene and a key member of the MEK signaling pathway. The $3^{\prime} \mathrm{UTR}$ of KRAS contains a let-7 binding site SNP, rs61764370, referred to in the literature as KRAS-variant. Several case control studies have linked the KRAS-variant to increased risk of breast cancer, though the effect appears to be dependent on patient context (Table 3 ). Premenopausal, but not postmenopausal patients with variant $\mathrm{T} / \mathrm{G}$ or $\mathrm{G} / \mathrm{G}$ genotypes were shown to have greater risk of TNBC (OR 1.64; CI 0.79-3.43, and OR 0.77; CI 0.51-1.16, respectively) [45]. Further analysis of KRAS-variant tumors in this study found an increase in MAPK signaling and a lower expression of let-7 via NF-KB-mediated activation of LIN-28, and a distinct gene expression pattern for KRAS-variant tumors [46]. Notably, the KRAS-variant also associated strongly with ER/PR negative premenopausal patients, implying that age and hormonal status play a role in $K R A S$-variant-associated risk [45].

A study in Iranian patients also found that patients with $\mathrm{T}>\mathrm{G}$ variant genotypes had a higher risk of developing breast cancer relative to TT genotypes (TT vs. GG + GT: OR = 3.55, CI 1.31-9.65, $p=0.012)$. Also, during G-T allele comparison, the $\mathrm{G}$ allele was found to be a risk factor for breast cancer (OR $=3.44$, CI 1.28-9.29, $p=0.013$ ) (Table 3) [47]. Notably, this study did not find significant associations between the KRAS-variant and patient age, ER, or HER2 status.

$K R A S$-variant-associated breast cancer risk appears to be impacted by estrogen withdrawal. McVeigh and colleagues observed that withdrawal from hormone replacement therapy (HRT) was linked to a higher rate of TNBC in KRAS-variant patients $(p<0.001)$. Furthermore, patients who previously used HRT and had the KRAS-variant tended to be diagnosed with higher grade tumors compared to non-variant patients who had previously been on HRT (2.33 vs. $1.98, p=0.029)$, indicating that overall the KRAS-variant is predictive of an aggressive tumor biology in patients with low estrogen or experiencing abrupt estrogen withdrawal (Table 3). They also evaluated the effect of estrogen deficiency on cell transformation ability in vitro using isogenic MCF10A breast epithelial cells bearing KRAS-variant and wild type genotypes. The in vitro study results agreed with clinical conclusions that estrogen withdrawal in KRAS-variant cells caused oncogenic transformations in isogenic cell lines. KRAS-variant TNBC patients also exhibited significantly elevated aromatase and ER $\beta$ expression, which are chiefly regulated by let-7 that is lower in KRAS-variant tumors [48].

Similarly, Cerne and colleagues reported the association of the KRAS-variant with HER2 overexpression in breast cancer in postmenopausal women. While prevalence of the KRAS-variant was 
similar in hormone receptor $(\mathrm{HR})+$ and HR-cases, 3 times as many variant patients had HER2 + $(42.9 \%)$ versus HER2-(13.3\%) tumors, and KRAS-variant tumors had significantly higher histopathological grades [49]. In contrast, a separate group found $20 \%$ of $K R A S$ - variant $\mathrm{T}>\mathrm{G}$ breast cancer cases in a Czech population to be HER2 negative, and 3\% of KRAS-variant cases to be HER2 positive. However, this study did not segregate data based on patient age or menopausal status. This may imply that KRAS-variant status affects HER2 expression in developing breast cancer, which is age dependent [50].

Notably, GWAS studies of a SNP linked to rs61764370 did not find significant association with risk of breast or ovarian cancer [51]. However, well-constructed case control studies that stratify patients by age [52], hormone levels [48], or Her2 status [49,50] have found significant associations between the KRAS-variant and $\mathrm{BC}$ risk and biology. Together, these data highlight the importance of proper contextualization of miR-SNPs like the KRAS-variant when determining patient risk, and suggest that large cohorts with less robust clinical annotation may not be the best place to define the clinical biology and utility of miR-SNPs, which are clearly context dependent, being influenced by environmental conditions, such as estrogen.

\section{5. miRNA-Coding SNPs}

SNPs within the mature or primary miRNA sequence can have significant effects on miRNA binding or processing [53]. Several SNPs acting directly on miRNA primary sequences or on upstream regulatory elements have been reported with significant effects on risk and prognosis of breast cancer. These miR-SNPs also have different effects between studies, again highlighting the role of patient context in using these SNPs to predict patient risk or prognosis.

miR27a: The G allele of miR-SNP rs895819 (A > G), identified on pre-miR-27a, is reported to be associated with a significantly reduced risk of breast cancer in variant patients $(\mathrm{OR}=0.88$; 95\% CI: 0.78-0.99) compared to controls in a German study cohort [54]. Meta-analysis later confirmed that the presence of a $G$ allele was significantly associated with diminished breast cancer risk ( $G$ vs. A; $\mathrm{OR}=0.91,95 \% \mathrm{CI}=0.86-0.97$ ) (Table 3) [55]. However, this analysis found that rs895819 is linked with reduced risk of breast cancer development in Caucasian, but not Asian populations [55]. On the contrary, Feng and colleagues observed that rs895819 SNP was linked to an elevated risk of breast cancer in Asian populations (AG + GG vs. AA: OR $=1.24 ; \mathrm{CI} 1.03-1.50, p=0.02$ ) [56]. The G variant of this SNP has been shown to alter the secondary structure of pre-miR-27a, resulting in reduction of familial breast cancer risk in younger women (age $<50$ years) [57]. It has been reported that the presence of a G allele variant at a terminal position in the pre-miR-27a hairpin could affect secondary structure, leading to cleavage inhibition and impaired processing. This results in the reduced expression of mature miR-27a, exerting a protective effect against breast cancer development, as observed in a Chinese case-control study (OR = 0.535; CI 0.321-0.891) (Table 3) [58].

miR-196a2: pre-miR-196a2 has a SNP, rs11614913, whose CC/CT genotypes have been linked to elevated breast cancer susceptibility in Chinese women, as assessed by a case-control study ( $\mathrm{OR}=2.20$; $\mathrm{CI}=1.19-4.09, p<0.01)$ and a clinical pathological study $(p<0.01)$ [59]. A variant $\mathrm{C}$ allele SNP causes impairment of mature miRNA expression, leading to decreased mature miR-196a2 levels and increased expression of the miR-196a 2 target HOXBP $[19,60]$. The miR-SNP-induced decline in miRNA expression could be utilized as a predictive biomarker for evaluating breast cancer risk in Chinese populations [59]. However, other studies have implied that rs 11614913 polymorphism predicts decreased risk of breast cancer in some populations [61]. Meta-analysis of 16 studies showed decreased risk of breast cancer in Caucasian variant patients ( $\mathrm{OR}=0.93$, CI 0.87-1.00, $p=0.044$ ), with no significant effects on risk in overall populations [62]. In contrast, several meta-analyses reported that CC genotype-bearing individuals of this SNP were more prone to breast cancer risk [OR $=0.906$, $\mathrm{CI}=0.825-0.995]$ (Table 3) [57,63]. Based on these conflicting results, the effects of miR-196a2 on breast cancer risk may be contextually dependent on other patient factors.

miR-499: The pre-miR region of miR-499 encodes a SNP, rs3746444, with alleles A and G, in which variant $G$ induces a higher risk $(O R=1.25$; $C I$ 1.02-1.51) of developing breast cancer in Chinese 
populations but not in Caucasian populations (Table 3) [64]. In addition, the $G$ allele variant of rs3746444 SNP was shown to be associated with a higher breast cancer risk (OR = 1.10; CI 1.01-1.20) in Asian populations, as assessed by meta-analysis [65]. Inversely, Asian populations bearing the T allele of the miR-SNP are predicted to have reduced breast cancer risk, while Caucasian populations are observed to be at an elevated risk of breast cancer for the same variant. This demonstrates the importance of considering ethnicity variations under consideration, while determining breast cancer risk [66].

Table 3. miR-SNPs Associated with Breast Cancer Risk Prediction.

\begin{tabular}{ccccc}
\hline SNP & Affected miRNA & Related Gene & Breast Cancer Association & References \\
\hline rs895819 $(\mathrm{A}>\mathrm{G})$ & pre-miRNA-27a & MIR27a & Reduced risk & {$[54,55,57,58,67]$} \\
rs61764370 & $3^{\prime}$ UTR of let-7 & KRAS & Elevated risk & {$[45,47,48,68-70]$} \\
rs11614913 & pre-miR-196a2 & MIR196a2 & Elevated risk & {$[57,59,63]$} \\
rs3746444 & miR-499 & MIR499 & Elevated risk & {$[64,66,71]$} \\
\hline
\end{tabular}

\section{Conclusions}

Use of miRNA-binding site SNPs as predictive biomarkers holds immense potential as it allows risk stratification for cancer development and cancer biology. This opens up additional avenues of designing efficient prevention strategies, and ensuring cost-effective applications of advanced diagnostic tests [72]. Work remains to be done to get a greater understanding of the function of miR-SNPs in context, since risk appears to be dependent on factors such as patient age, hormone status, and ethnicity. Additionally, the prognostic potential of SNPs in several key miRNA regulatory pathways has yet to be determined. For example, recent research has highlighted the utility of noncoding RNA networks on both miRNA function $[73,74]$ and as breast cancer biomarkers $[75,76]$, but no current studies have linked miR-SNPs in competing endogenous RNAs to breast cancer risk or prognosis. Elaborate and well-characterized case-control studies covering diverse populations of varying ethnicities and from geographic locations, including studies on novel targets, will be an invaluable asset in developing microRNA target SNP-based gene analysis [13]. These studies could distinguish specific contexts for miR-SNPs, whether in 3'UTRs, miRNA biogenesis genes, or in miRNAs themselves, to serve as predictive markers for breast cancer risk and prognosis. An in-depth knowledge of miR-SNP working mechanisms can aid in categorizing individuals according to cancer susceptibility and prediction of subtypes. Further characterization of miR-SNPs and their contextual effects stands to significantly improve patient treatment accuracy and efficacy, as well as aiding in development of predictive biomarkers, both in terms of cancer development and aggressiveness.

Author Contributions: Conceptualization, J.B.W.; Writing-Original Draft Preparation, P.M.; Writing-Review \& Editing, P.M., G.H.R. and J.B.W; Supervision, J.B.W.; Funding Acquisition, J.B.W.

Funding: Dr. Weidhaas was supported by a grant from the NIH (CA157749). The funding body had no role in the design or writing of the manuscript.

Conflicts of Interest: Dr. Weidhaas discovered the KRAS-variant, which was patented by Yale University, and is licensed to a company that she co-founded, MiraDx. The other authors declare no conflict of interest.

\section{References}

1. US Breast Cancer Statistics. Available online: https://www.breastcancer.org/symptoms/understand_bc/ statistics (accessed on 14 January 2019).

2. How Common is Breast Cancer? Available online: https://www.cancer.org/cancer/breast-cancer/about/ how-common-is-breast-cancer.html (accessed on 14 January 2019).

3. Vogel, V. Approaches to Understanding Breast Cancer. In The Breast; Bland, K.K.VS., Copeland, E.M., Gradishar, W.J., Eds.; Elsevier: Amsterdam, The Netherlands, 2018; pp. 207-218. 
4. Calin, G.A.; Dumitru, C.D.; Shimizu, M.; Bichi, R.; Zupo, S.; Noch, E.; Aldler, H.; Rattan, S.; Keating, M.; Rai, K.; et al. Frequent deletions and down-regulation of micro- RNA genes miR15 and miR16 at 13q14 in chronic lymphocytic leukemia. Proc. Natl. Acad. Sci. USA 2002, 99, 15524-15529. [CrossRef] [PubMed]

5. Frixa, T.; Donzelli, S.; Blandino, G. Oncogenic MicroRNAs: Key Players in Malignant Transformation. Cancers 2015, 7, 2466-2485. [CrossRef] [PubMed]

6. Nguyen-Dien, G.T.; Smith, R.A.; Haupt, L.M.; Griffiths, L.R.; Nguyen, H.T. Genetic polymorphisms in miRNAs targeting the estrogen receptor and their effect on breast cancer risk. Meta Gene 2014, 2, 226-236. [CrossRef] [PubMed]

7. Gordon, O. Emery and Rimoin's Principles and Practice of Medical Genetics; Rimoin, D.P.R., Korf, B., Eds.; Academic Press: Cambridge, MA, USA, 2013; pp. 1-31.

8. Murata, M.; Thompson, P.E. Two-nucleotide codon change in a hemoglobin polymorphism of the Celebes black ape (Macaca nigra). Biochem. Genet. 1976, 14, 183-195. [CrossRef] [PubMed]

9. Auton, A.; Brooks, L.D.; Durbin, R.M.; Garrison, E.P.; Kang, H.M.; Korbel, J.O.; Marchini, J.L.; McCarthy, S.; McVean, G.A.; Abecasis, G.R. A global reference for human genetic variation. Nature 2015, 526, 68-74. [PubMed]

10. Salzman, D.W.; Weidhaas, J.B. SNPing cancer in the bud: microRNA and microRNA-target site polymorphisms as diagnostic and prognostic biomarkers in cancer. Pharmacol. Ther. 2013, 137, 55-63. [CrossRef] [PubMed]

11. Yuan, Y.; Weidhaas, J.B. Functional microRNA binding site variants. Mol. Oncol. 2019, 13, 4-8.

12. Zheng, H.; Song, F.; Zhang, L.; Yang, D.; Ji, P.; Wang, Y.; Almeida, M.; Calin, G.A.; Hao, X.; Wei, Q.; et al. Genetic variants at the miR-124 binding site on the cytoskeleton-organizing IQGAP1 gene confer differential predisposition to breast cancer. Int. J. Oncol. 2011, 38, 1153-1161. [CrossRef]

13. Chen, K.; Song, F.; Calin, G.A.; Wei, Q.; Hao, X.; Zhang, W. Polymorphisms in microRNA targets: A gold mine for molecular epidemiology. Carcinogenesis 2008, 29, 1306-1311. [CrossRef]

14. Nicoloso, M.S.; Sun, H.; Spizzo, R.; Kim, H.; Wickramasinghe, P.; Shimizu, M.; Wojcik, S.E.; Ferdin, J.; Kunej, T.; Xiao, L.; et al. Single-nucleotide polymorphisms inside microRNA target sites influence tumor susceptibility. Cancer Res. 2010, 70, 2789-2798. [CrossRef]

15. Ryan, B.M.; Robles, A.I.; Harris, C.C. Genetic variation in microRNA networks: The implications for cancer research. Nat. Rev. Cancer 2010, 10, 389-402. [CrossRef] [PubMed]

16. Song, X.; Zhong, H.; Wu, Q.; Wang, M.; Zhou, J.; Zhou, Y.; Lu, X.; Ying, B. Association between SNPs in microRNA machinery genes and gastric cancer susceptibility, invasion, and metastasis in Chinese Han population. Oncotarget 2017, 8, 86435-86446. [CrossRef]

17. Guo, Z.; Shu, Y.; Zhou, H.; Zhang, W. Identification of diagnostic and prognostic biomarkers for cancer: Focusing on genetic variations in microRNA regulatory pathways (Review). Mol. Med. Rep. 2016, 13, 1943-1952. [CrossRef] [PubMed]

18. Ryan, B. Advances in Cancer Research; Croce, C.F.P.B., Ed.; Academic Press: Cambridge, MA, USA, 2017; pp. 151-171.

19. Hoffman, A.E.; Zheng, T.; Yi, C.; Leaderer, D.; Weidhaas, J.; Slack, F.; Zhang, Y.; Paranjape, T.; Zhu, Y. microRNA miR-196a-2 and breast cancer: A genetic and epigenetic association study and functional analysis. Cancer Res. 2009, 69, 5970-5977. [CrossRef] [PubMed]

20. Sung, H.; Lee, K.M.; Choi, J.Y.; Han, S.; Lee, J.Y.; Li, L.; Park, S.K.; Yoo, K.Y.; Noh, D.Y.; Ahn, S.H.; et al. Common genetic polymorphisms of microRNA biogenesis pathway genes and risk of breast cancer: A case-control study in Korea. Breast Cancer Res. Treat. 2011, 130, 939-951. [CrossRef] [PubMed]

21. Sung, H.; Jeon, S.; Lee, K.M.; Han, S.; Song, M.; Choi, J.Y.; Park, S.K.; Yoo, K.Y.; Noh, D.Y.; Ahn, S.H.; et al. Common genetic polymorphisms of microRNA biogenesis pathway genes and breast cancer survival. BMC Cancer 2012, 12, 195. [CrossRef]

22. Bartel, D.P. MicroRNAs: Genomics, biogenesis, mechanism, and function. Cell 2004, 116, 281-297. [CrossRef]

23. Kroliczewski, J.; Sobolewska, A.; Lejnowski, D.; Collawn, J.F.; Bartoszewski, R. microRNA single polynucleotide polymorphism influences on microRNA biogenesis and mRNA target specificity. Gene 2018, 640, 66-72. [CrossRef]

24. Jiang, Y.; Chen, J.; Wu, J.; Hu, Z.; Qin, Z.; Liu, X.; Guan, X.; Wang, Y.; Han, J.; Jiang, T.; et al. Evaluation of genetic variants in microRNA biosynthesis genes and risk of breast cancer in Chinese women. Int. J. Cancer 2013, 133, 2216-2224. [CrossRef] 
25. Leaderer, D.; Hoffman, A.E.; Zheng, T.; Fu, A.; Weidhaas, J.; Paranjape, T.; Zhu, Y. Genetic and epigenetic association studies suggest a role of microRNA biogenesis gene exportin-5 (XPO5) in breast tumorigenesis. Int. J. Mol. Epidemiol. Genet. 2011, 2, 9-18.

26. Ma, H.; Yuan, H.; Yuan, Z.; Yu, C.; Wang, R.; Jiang, Y.; Hu, Z.; Shen, H.; Chen, N. Genetic Variations in Key MicroRNA Processing Genes and Risk of Head and Neck Cancer: A Case-Control Study in Chinese Population. PLoS ONE 2012, 7, e47544. [CrossRef] [PubMed]

27. Yu, Y.Y.; Kuang, D.; Yin, X.X. Association between the DICER rs1057035 polymorphism and cancer risk: Evidence from a meta-analysis of 12,675 individuals. Asian Pac. J. Cancer Prev. APJCP 2015, 16, 119-124. [CrossRef] [PubMed]

28. Cao, J.; Luo, C.; Peng, R.; Guo, Q.; Wang, K.; Wang, P.; Ye, H.; Song, C. MiRNA-binding site functional polymorphisms in DNA repair genes RAD51, RAD52, and XRCC2 and breast cancer risk in Chinese population. Tumour Biol. 2016. [CrossRef] [PubMed]

29. Jiang, Y.; Qin, Z.; Hu, Z.; Guan, X.; Wang, Y.; He, Y.; Xue, J.; Liu, X.; Chen, J.; Dai, J.; et al. Genetic variation in a hsa-let-7 binding site in RAD52 is associated with breast cancer susceptibility. Carcinogenesis 2013, 34, 689-693. [CrossRef] [PubMed]

30. Dorairaj, J.J.; Salzman, D.W.; Wall, D.; Rounds, T.; Preskill, C.; Sullivan, C.A.; Lindner, R.; Curran, C.; Lezon-Geyda, K.; McVeigh, T.; et al. A germline mutation in the BRCA1 3'UTR predicts Stage IV breast cancer. BMC Cancer 2014, 14, 421. [CrossRef] [PubMed]

31. Pelletier, C.; Speed, W.C.; Paranjape, T.; Keane, K.; Blitzblau, R.; Hollestelle, A.; Safavi, K.; van den Ouweland, A.; Zelterman, D.; Slack, F.J.; et al. Rare BRCA1 haplotypes including 3'UTR SNPs associated with breast cancer risk. Cell Cycle 2011, 10, 90-99. [CrossRef] [PubMed]

32. Pongsavee, M.; Yamkamon, V.; Dakeng, S.; P, O.c.; Smith, D.R.; Saunders, G.F.; Patmasiriwat, P. The BRCA1 3'-UTR: $5711+421 \mathrm{~T} / \mathrm{T} \_5711+1286 \mathrm{~T} / \mathrm{T}$ genotype is a possible breast and ovarian cancer risk factor. Genet. Test. Mol. Biomark. 2009, 13, 307-317. [CrossRef]

33. Newman, B.; Mu, H.; Butler, L.M.; Millikan, R.C.; Moorman, P.G.; King, M.C. Frequency of breast cancer attributable to BRCA1 in a population-based series of American women. Jama 1998, 279, 915-921. [CrossRef]

34. Yang, F.; Chen, F.; Xu, J.; Guan, X. Identification and frequency of the rs12516 and rs8176318 BRCA1 gene polymorphisms among different populations. Oncol. Lett. 2016, 11, 2481-2486. [CrossRef]

35. Erturk, E.; Cecener, G.; Polatkan, V.; Gokgoz, S.; Egeli, U.; Tunca, B.; Tezcan, G.; Demirdogen, E.; Ak, S.; Tasdelen, I. Evaluation of genetic variations in miRNA-binding sites of BRCA1 and BRCA2 genes as risk factors for the development of early-onset and/or familial breast cancer. Asian Pac. J. Cancer Prev. APJCP 2014, 15, 8319-8324. [CrossRef]

36. Brendle, A.; Lei, H.; Brandt, A.; Johansson, R.; Enquist, K.; Henriksson, R.; Hemminki, K.; Lenner, P.; Försti, A. Polymorphisms in predicted microRNA-binding sites in integrin genes and breast cancer: ITGB4 as prognostic marker. Carcinogenesis 2008, 29, 1394-1399. [CrossRef] [PubMed]

37. Tchatchou, S.; Jung, A.; Hemminki, K.; Sutter, C.; Wappenschmidt, B.; Bugert, P.; Weber, B.H.; Niederacher, D.; Arnold, N.; Varon-Mateeva, R.; et al. A variant affecting a putative miRNA target site in estrogen receptor (ESR) 1 is associated with breast cancer risk in premenopausal women. Carcinogenesis 2009, 30, 59-64. [CrossRef]

38. Fishman, J.; Osborne, M.P.; Telang, N.T. The role of estrogen in mammary carcinogenesis. Ann. N. Y. Acad. Sci. 1995, 768, 91-100. [CrossRef] [PubMed]

39. Martin, G.; Davio, C.; Rivera, E.; Melito, G.; Cricco, G.; Andrade, N.; Caro, R.; Bergoc, R. Hormone dependence of mammary tumors induced in rats by intraperitoneal NMU injection. Cancer Investig. 1997, 15, 8-17. [CrossRef]

40. Forma, E.; Brzeziańska, E.; Krześlak, A.; Chwatko, G.; Jóźwiak, P.; Szymczyk, A.; Smolarz, B.;

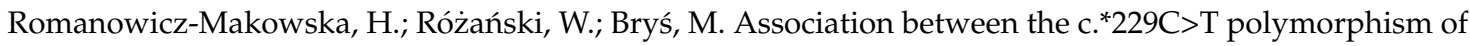
the topoisomerase II $\beta$ binding protein 1 (TopBP1) gene and breast cancer. Mol. Biol. Rep. 2013, 40, 3493-3502. [CrossRef] [PubMed]

41. Forma, E. TopBP1 in DNA Damage Response. In DNA Repair; Kruman, I., Ed.; INTECH Open Access Publisher: Rijeka, Croatia, 2011; Volume 4, pp. 281-304.

42. Rolli, M.; Fransvea, E.; Pilch, J.; Saven, A.; Felding-Habermann, B. Activated integrin alphavbeta3 cooperates with metalloproteinase MMP-9 in regulating migration of metastatic breast cancer cells. Proc. Natl. Acad. Sci. USA 2003, 100, 9482-9487. [CrossRef] 
43. Ren, F.; Tang, R.; Zhang, X.; Madushi, W.M.; Luo, D.; Dang, Y.; Li, Z.; Wei, K.; Chen, G. Overexpression of MMP Family Members Functions as Prognostic Biomarker for Breast Cancer Patients: A Systematic Review and Meta-Analysis. PLoS ONE 2015, 10, e0135544. [CrossRef]

44. Pirooz, H.J.; Jafari, N.; Rastegari, M.; Fathi-Roudsari, M.; Tasharrofi, N.; Shokri, G.; Tamadon, M.; Sazegar, H.; Kouhkan, F. Functional SNP in microRNA-491-5p binding site of MMP9 3'-UTR affects cancer susceptibility. J. Cell. Biochem. 2018, 119, 5126-5134. [CrossRef] [PubMed]

45. Paranjape, T.; Heneghan, H.; Lindner, R.; Keane, F.K.; Hoffman, A.; Hollestelle, A.; Dorairaj, J.; Geyda, K.; Pelletier, C.; Nallur, S.; et al. A $3^{\prime}$-untranslated region KRAS variant and triple-negative breast cancer: A case-control and genetic analysis. Lancet Oncol. 2011, 12, 377-386. [CrossRef]

46. Iliopoulos, D.; Hirsch, H.A.; Struhl, K. An epigenetic switch involving NF-kappaB, Lin28, Let-7 MicroRNA, and IL6 links inflammation to cell transformation. Cell 2009, 139, 693-706. [CrossRef]

47. Sanaei, S.; Hashemi, M.; Eskandari, E.; Hashemi, S.M.; Bahari, G. KRAS Gene Polymorphisms and their Impact on Breast Cancer Risk in an Iranian Population. Asian Pac. J. Cancer Prev. APJCP 2017, 18, 1301-1305.

48. McVeigh, T.P.; Jung, S.Y.; Kerin, M.J.; Salzman, D.W.; Nallur, S.; Nemec, A.A.; Dookwah, M.; Sadofsky, J.; Paranjape, T.; Kelly, O.; et al. Estrogen withdrawal, increased breast cancer risk and the KRAS-variant. Cell Cycle 2015, 14, 2091-2099. [CrossRef] [PubMed]

49. Cerne, J.Z.; Stegel, V.; Gersak, K.; Novakovic, S. KRAS rs61764370 is associated with HER2-overexpressed and poorly-differentiated breast cancer in hormone replacement therapy users: A case control study. BMC Cancer 2012, 12, 105. [CrossRef]

50. Uvirova, M.; Simova, J.; Kubova, B.; Dvorackova, N.; Tomaskova, H.; Sedivcova, M.; Dite, P. Comparison of the prevalence of KRAS-LCS6 polymorphism (rs61764370) within different tumour types (colorectal, breast, non-small cell lung cancer and brain tumours). A study of the Czech population. Biomed. Pap. 2015, 159, 466-471. [CrossRef] [PubMed]

51. Hollestelle, A.; van der Baan, F.H.; Berchuck, A.; Johnatty, S.E.; Aben, K.K.; Agnarsson, B.A.; Aittomaki, K.; Alducci, E.; Andrulis, I.L.; Anton-Culver, H.; et al. No clinical utility of KRAS variant rs61764370 for ovarian or breast cancer. Gynecol. Oncol. 2016, 141, 386-401. [CrossRef]

52. Ustinova, M.; Daneberga, Z.; Berzina, D.; Nakazawa-Miklasevica, M.; Maksimenko, J.; Gardovskis, J.; Miklasevics, E. Impact of KRAS variant rs61764370 on breast cancer morbidity. Exp. Oncol. 2015, 37, $292-294$. [CrossRef]

53. Duan, R.; Pak, C.; Jin, P. Single nucleotide polymorphism associated with mature miR-125a alters the processing of pri-miRNA. Hum. Mol. Genet. 2007, 16, 1124-1131. [CrossRef] [PubMed]

54. Yang, R.; Schlehe, B.; Hemminki, K.; Sutter, C.; Bugert, P.; Wappenschmidt, B.; Volkmann, J.; Varon, R.; Weber, B.H.; Niederacher, D.; et al. A genetic variant in the pre-miR-27a oncogene is associated with a reduced familial breast cancer risk. Breast Cancer Res. Treat. 2010, 121, 693-702. [CrossRef] [PubMed]

55. Chen, M.; Fang, W.; Wu, X.; Bian, S.; Chen, G.; Lu, L.; Weng, Y. Distinct effects of rs895819 on risk of different cancers: An update meta-analysis. Oncotarget 2017, 8, 75336-75349. [CrossRef] [PubMed]

56. Feng, Y.; Duan, F.; Song, C.; Zhao, X.; Dai, L.; Cui, S. Systematic evaluation of cancer risk associated with rs2292832 in miR-149 and rs895819 in miR-27a: A comprehensive and updated meta-analysis. Oncotarget 2016, 7, 22368-22384. [CrossRef]

57. Ferracin, M.; Querzoli, P.; Calin, G.A.; Negrini, M. MicroRNAs: Toward the clinic for breast cancer patients. Semin. Oncol. 2011, 38, 764-775. [CrossRef]

58. Zhang, N.; Huo, Q.; Wang, X.; Chen, X.; Long, L.; Jiang, L.; Ma, T.; Yang, Q. A genetic variant in pre-miR-27a is associated with a reduced breast cancer risk in younger Chinese population. Gene 2013, 529, 125-130. [CrossRef] [PubMed]

59. Qi, P.; Wang, L.; Zhou, B.; Yao, W.J.; Xu, S.; Zhou, Y.; Xie, Z.B. Associations of miRNA polymorphisms and expression levels with breast cancer risk in the Chinese population. Genet. Mol. Res. GMR 2015, 14, 6289-6296. [CrossRef] [PubMed]

60. Yekta, S.; Shih, I.H.; Bartel, D.P. MicroRNA-directed cleavage of HOXB8 mRNA. Science 2004, 304, 594-596. [CrossRef] [PubMed]

61. Dai, Z.M.; Kang, H.F.; Zhang, W.G.; Li, H.B.; Zhang, S.Q.; Ma, X.B.; Lin, S.; Wang, M.; Feng, Y.J.; Liu, K.; et al. The Associations of Single Nucleotide Polymorphisms in miR196a2, miR-499, and miR-608 With Breast Cancer Susceptibility: A STROBE-Compliant Observational Study. Medicine 2016, 95, e2826. [CrossRef] [PubMed] 
62. Zhang, H.; Zhang, Y.; Yan, W.; Wang, W.; Zhao, X.; Ma, X.; Gao, X.; Zhang, S. Association between three functional microRNA polymorphisms (miR-499 rs3746444, miR-196a rs11614913 and miR-146a rs2910164) and breast cancer risk: A meta-analysis. Oncotarget 2016, 8, 393-407. [CrossRef]

63. Wang, P.Y.; Gao, Z.H.; Jiang, Z.H.; Li, X.X.; Jiang, B.F.; Xie, S.Y. The associations of single nucleotide polymorphisms in miR-146a, miR-196a and miR-499 with breast cancer susceptibility. PLoS ONE 2013, 8, e70656. [CrossRef]

64. Hu, Z.; Liang, J.; Wang, Z.; Tian, T.; Zhou, X.; Chen, J.; Miao, R.; Wang, Y.; Wang, X.; Shen, H. Common genetic variants in pre-microRNAs were associated with increased risk of breast cancer in Chinese women. Hum. Mutat. 2009, 30, 79-84. [CrossRef] [PubMed]

65. Wang, L.; Liu, W.; Jiang, W.; Lin, J.; Jiang, Y.; Li, B.; Pang, D. A miRNA binding site single-nucleotide polymorphism in the $3^{\prime}$-UTR region of the IL23R gene is associated with breast cancer. PLoS ONE 2012, 7, e49823. [CrossRef]

66. Chen, Q.H.; Wang, Q.B.; Zhang, B. Ethnicity modifies the association between functional microRNA polymorphisms and breast cancer risk: A HuGE meta-analysis. Tumour Biol. 2014, 35, 529-543. [CrossRef]

67. Catucci, I.; Verderio, P.; Pizzamiglio, S.; Bernard, L.; Dall'olio, V.; Sardella, D.; Ravagnani, F.; Galastri, L.; Barile, M.; Peissel, B.; et al. The SNP rs895819 in miR-27a is not associated with familial breast cancer risk in Italians. Breast Cancer Res. Treat. 2012, 133, 805-807. [CrossRef]

68. Crowley, E.H.; Arena, S.; Lamba, S.; Di Nicolantonio, F.; Bardelli, A. Targeted knock-in of the polymorphism rs61764370 does not affect KRAS expression but reduces let-7 levels. Hum. Mutat. 2014, 35, 208-214. [CrossRef] [PubMed]

69. Pilarski, R.; Patel, D.A.; Weitzel, J.; McVeigh, T.; Dorairaj, J.J.; Heneghan, H.M.; Miller, N.; Weidhaas, J.B.; Kerin, M.J.; McKenna, M.; et al. The KRAS-variant is associated with risk of developing double primary breast and ovarian cancer. PLoS ONE 2012, 7, e37891. [CrossRef] [PubMed]

70. Hollestelle, A.; Pelletier, C.; Hooning, M.; Crepin, E.; Schutte, M.; Look, M.; Collee, J.M.; Nieuwlaat, A.; Dorssers, L.C.; Seynaeve, C.; et al. Prevalence of the variant allele rs61764370 T>G in the 3'UTR of KRAS among Dutch BRCA1, BRCA2 and non-BRCA1/BRCA2 breast cancer families. Breast Cancer Res. Treat. 2011, 128, 79-84. [CrossRef] [PubMed]

71. Wang, W.Y.; Chien, Y.C.; Wong, Y.K.; Lin, Y.L.; Lin, J.C. Effects of KRAS mutation and polymorphism on the risk and prognosis of oral squamous cell carcinoma. Head Neck 2012, 34, 663-666. [CrossRef]

72. Paranjape, T.; Slack, F.J.; Weidhaas, J.B. MicroRNAs: Tools for cancer diagnostics. Gut 2009, 58, $1546-1554$. [CrossRef] [PubMed]

73. Salmena, L.; Poliseno, L.; Tay, Y.; Kats, L.; Pandolfi, P.P. A ceRNA hypothesis: The Rosetta Stone of a hidden RNA language? Cell 2011, 146, 353-358. [CrossRef]

74. Su, X.; Xing, J.; Wang, Z.; Chen, L.; Cui, M.; Jiang, B. microRNAs and ceRNAs: RNA networks in pathogenesis of cancer. Chinese J. Cancer Res. 2013, 25, 235-239.

75. Chen, J.; Xu, J.; Li, Y.; Zhang, J.; Chen, H.; Lu, J.; Wang, Z.; Zhao, X.; Xu, K.; Li, Y.; et al. Competing endogenous RNA network analysis identifies critical genes among the different breast cancer subtypes. Oncotarget 2016, 8, 10171-10184. [CrossRef] [PubMed]

76. Abdollahzadeh, R.; Daraei, A.; Mansoori, Y.; Sepahvand, M.; Amoli, M.M.; Tavakkoly-Bazzaz, J. Competing endogenous RNA (ceRNA) cross talk and language in ceRNA regulatory networks: A new look at hallmarks of breast cancer. J. Cell. Physiol. 2018. [CrossRef] [PubMed]

(C) 2019 by the authors. Licensee MDPI, Basel, Switzerland. This article is an open access article distributed under the terms and conditions of the Creative Commons Attribution (CC BY) license (http://creativecommons.org/licenses/by/4.0/). 